\title{
Partial Discharge Assessment of XLPE Cable
}

\author{
Manish Kumar Singla, Jyoti Gupta, Parag Nijhawan, Ashish Paramane
}

\begin{abstract}
Rapid growth in power system has created the opportunity in the field of materials to ensure reliable operation of various equipments throughout their operating life span. Due to the cumulative effects of mechanical, chemical and electrical stresses caused by the partial discharge (PD), insulation gradually degrades. Partial Discharge tests ensure the good quality of cable insulation like cross-linked polyethylene (XLPE) under high voltage conditions. This paper describes the results of a real testing based experiment of Partial Discharge with XLPE cable. Under the application of different voltages, the breakdown level of cable insulation is checked in the laboratory experimental setup. The MATLAB Simulink architecture of test system with $P D$ structure is constructed in correlation with laboratory experiments. The results of both the simulation and the laboratory experiment have been compared in this work. The standard deviation and percentage error are calculated for the simulated and experimental data.
\end{abstract}

Keywords- Partial discharge; high voltage; cross-linked polyethylene; voltage pulse; insulating material.

\section{INTRODUCTION}

High voltage direct current (HVDC) plays an important role in the area of energy distribution field (Sharad, P. A., \& Kumar, K. S. 2017), (Singla, M. K., et.al. 2018), (Sharad, P. A., \& Kumar, K. S. 2016) especially intensive environmental and energy saving conditions. Insulation is also considered as the backbone of the HVDC. For the improvement of insulation system, various researches are going on. Different types of materials such as concrete, liquid, gaseous and their combination are used for the insulation purpose in HV power devices. Due to the cumulative effects of partial discharge (PD), there is gradually decrement in the quality of the insulation. The insulation is considered as a sensitive area for the particular device. Most insulators are not pure in nature i.e., they contain some impurities. The voltage withstand capability of insulating materials get affected due to the presence of impurities and/or bubbles of air (zero). These are responsible for the internal PD and hence, weaken the insulation. Electrical engineer safely handled, design and regular monitor the equipment insulation.

Revised Manuscript Received on October 30, 2019.

* Correspondence Author

Manish Kumar Singla, EIE Department, Thapar Institute of Engineering and Technology, Patiala (INDIA).

Jyoti Gupta, EIE Department, Thapar Institute of Engineering and Technology, Patiala (INDIA).

Parag Nijhawan, EIE Department, Thapar Institute of Engineering and Technology, Patiala (INDIA).

Ashish Paramane, EIE Department, Thapar Institute of Engineering and Technology, Patiala (INDIA).

(c) The Authors. Published by Blue Eyes Intelligence Engineering and Sciences Publication (BEIESP). This is an open access article under the CC BY-NC-ND license (http://creativecommons.org/licenses/by-nc-nd/4.0/)
Due to $\mathrm{PD}$, insulation failure occurs in $\mathrm{HV}$ power equipment. $\mathrm{PD}$ is always generated at poor conductor profiles in $\mathrm{HV}$ devices. For the above reasons, $\mathrm{PD}$ identification and measurement are essential for predicting instruments from insulation damage and it is necessary to reassure the long-term operation of HV power devices.

A PD which is one of the main fault and ageing mechanisms in an insulation system refers to a small spark like short circuits across parts of the insulation, an electrical discharge that does not completely bridge the electrodes.

It will gradually lead to degradation and ageing of the insulation. Consequently, the occurrence of PDs gives a good indication of the state of the insulation system. In the transformer and power cable for high voltage applications, the insulation quality is of utmost importance. The main cause of PD in any insulation is the presence of impurities. Cable design includes machine, man and material. Therefore, it is impossible to design a cable without any impurity.

Insulation of HVDC is made up of different type of material (liquid, solid and gaseous) and their combination (Singla, M. K., et.al. 2018). Initially in the starting ages of high voltage, porcelain was used as an insulator. Later on, silicone rubber was introduced which changed the basic structure of the insulation system due to its lightweight, high resistance and high tolerance to pollution.

Most important step while manufacturing of any HVDC equipment is the testing of the insulation. Breakdown test, dissipation factor measurement and resistance measurement are the important methods of testing the insulation (Naidu, M. S. 2013). The cavity and voids crack in the insulation raises the voltage discharge of lower spikes and the amount of deterioration depends upon level of voltage. Therefore, it becomes the main benchmark for insulation testing of HVDC equipments. The stress on the insulation system is determined by determining the size of the cavity and position of these voids.

$\mathrm{PD}$ is considered as the major source of decline in the insulation condition. Therefore, many researchers have tried to measure and detect PDs to maintain the reliability and security of the power system network. In (Weeks, W. L \&Diao, Y. M 1984) it is evaluated the effect of the semiconductor screen, surrounding earth and conductor on the transmission characteristics of transient wave in the power cable. The (Mugala, G et al., 2007) have developed an estimated model that can examine how the dielectric and conductor can contribute to the losses in the different parts of cable. For RF application, Loop antenna (De Mars, P. A et al., 1930) act as transmitter and receiver. The author of (Moore, P. J et al., 2006) has examined PD using extensive band RF antenna. Figure 1 shows a characteristics PD pulse. 


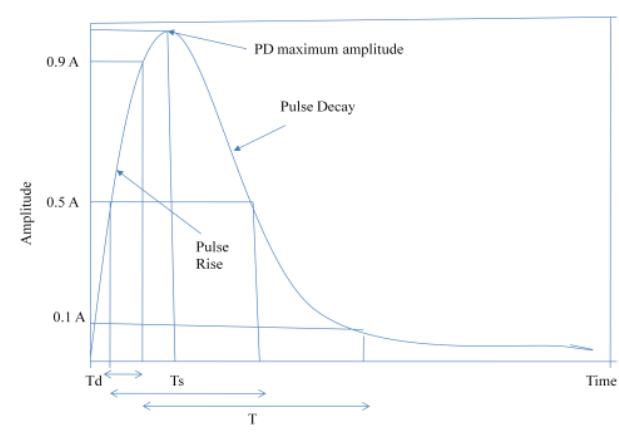

Figure 1 Characteristics of PD pulse (Patch, R \& Hoof, M 1998).

PD circuit diagram proposed in literature (Patch, R \& Hoof, $M$ 1998) known as capacitance model; represent the $P D$ characteristics in the test system with weak points like defects and impurities. A PD circuit diagram is shown below in Figure 2.

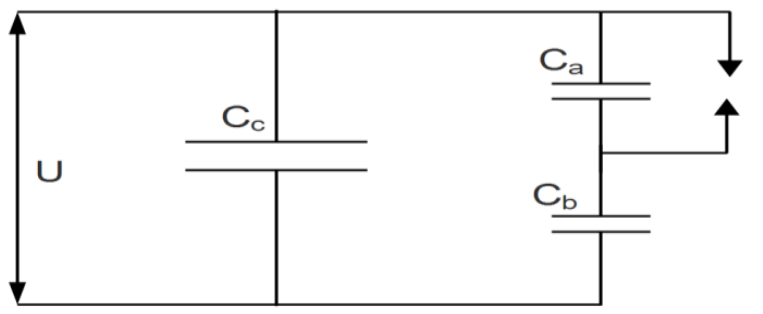

Figure 2 PD circuit diagram (Naidu, M. S. 2013).

Where

$\mathrm{C}_{\mathrm{a}}$ : cavity capacitor

$\mathrm{C}_{\mathrm{b}}$ : insulating material around cavity capacitor

$\mathrm{C}_{c}$ : remaining insulating material capacitor

$\mathrm{C}_{\mathrm{a}}$ and $\mathrm{C}_{\mathrm{b}}$ are not measurable

$\mathrm{U}$ : voltage power frequency

S: spark gap

\section{PARTIAL DISCHARGE}

\section{A. Definition}

"As per standard IEC 60270, localized electrical discharge which only partially bridges insulation in-between conductors and may or may not occur in adjacent to a conductor is termed as PD" (Kuffel, J \& Kuffel, P 2000). Materials used for the high voltage electrical insulation system are solid, gaseous and liquid. It is not possible to make pure insulation as manufacturing required many stages. Hence, insulation has some impurity in the form of cracks and voids. The equivalent circuit of an insulating device is shown in Figure 3.

Partial discharge is a local discharge, which cannot bridge the gap between the partially electrode. The manufacturing insulation process consists of several phases including selection of raw materials, preparation and processing and thermal or chemical treatment, when necessary, including the effect of human, machine, raw material and environment in providing electrical insulation for $\mathrm{HV}$ equipment. It is actually very difficult to have a perfect electrical insulation (Karmakar, S \& Sabat, A 2011).

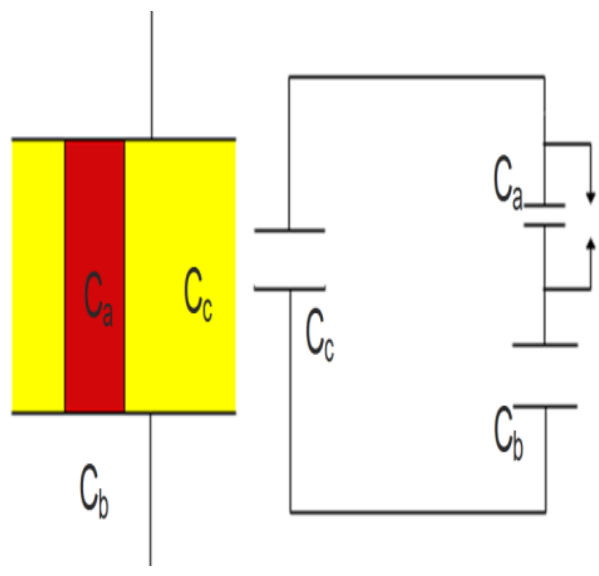

Figure 3 Insulating devices with a void $C_{a}$ and its equivalent circuit (Naidu, M. S. 2013).

Some types of defects contaminate varnish in air bubbles, voids, micro-cracks, insulation and inappropriate contact between the operations of the surface, winding wire etc.

\section{CABLES}

The cable insulation should have good toughness and tensile strength (Van Brunt, R. J 1994). It should have a low power factor and dielectric constant on the other side; it should also have high insulation resistance and dielectric strength. Apart from these, because of the heavy loading conditions, insulation can be unveiled to high temperatures for large periods of time. Therefore, it should be able to sustain against high temperatures. It should also be immune to various chemicals and long exposure to sunlight. High voltage cables also give rise to ozone gas, and the insulation will deteriorate in its presence (Bezborodko, P et al., 1989). This is particularly severe for the insulation near the conductors. Cables also have low absorption to water as they are laid in sea and rivers. Also, at low temperature operation of cables, insulation should not become brittle and/or stiff. Figure 4 shows the construction of low voltage cable.

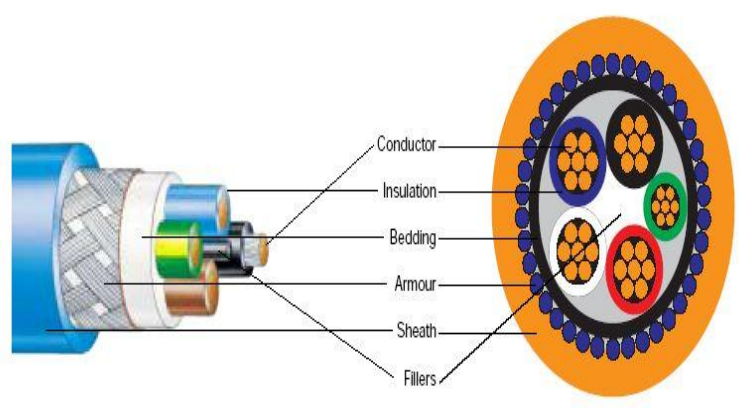

Figure 4 Low Voltage Cable (Bezborodko, P et al., 1989)

Different types of insulation used in cable industries are compressed gas, plastic, rubber, and paper. Paper insulating lead and sheath lead cables are still used due to their high dielectric strength, reliability, long life and low dielectric loss. Polyvinyl chloride (PVC),cross-linked polyethylene (XLPE) and polyethylene are also used for the low and medium voltage (up to $3.3 \mathrm{kV}$ ) cables. For HV application, PVC is not used as it has high loss, and its dielectric strength is constant.

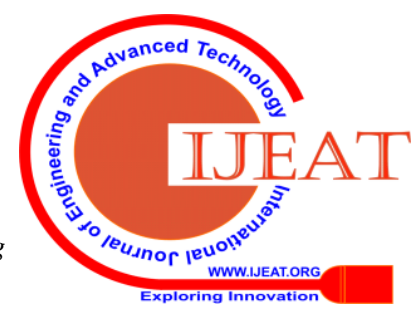




\section{A. Testing of Cables}

Cables are very important media for the transmission of electrical energy. For power engineers, large power transmission cables are important, and therefore, different types of test for electric cables have been reported in literature (Ametani, A et al., 2004). These tests are important to ensure that the satisfactory operation of cables under the most serious conditions in service.

Various tests can be categorized on cables, as follows:

(i) Mechanical testing such as bending testing and corrosion testing

(ii) Thermal duty test

(iii) Dielectric power factor test

(iv) Impulse withstand voltage test

(v) Partial discharge test

(vi) Life expectancy test

\section{B. High Voltage Tests on Cables}

Cable insulation is tested to withstand voltage like AC, DC, and impulse voltages. At the time of manufacture, the cable is passed through high voltage test at the rated voltage to check the continuation of the cable. Figure 5 shows the high voltage cable which is also known as shielded cable. As a regular test, cable is tested to implement an acc. 2.5 minute voltage rated price for 10 minutes. There should be no damage to cable insulation.

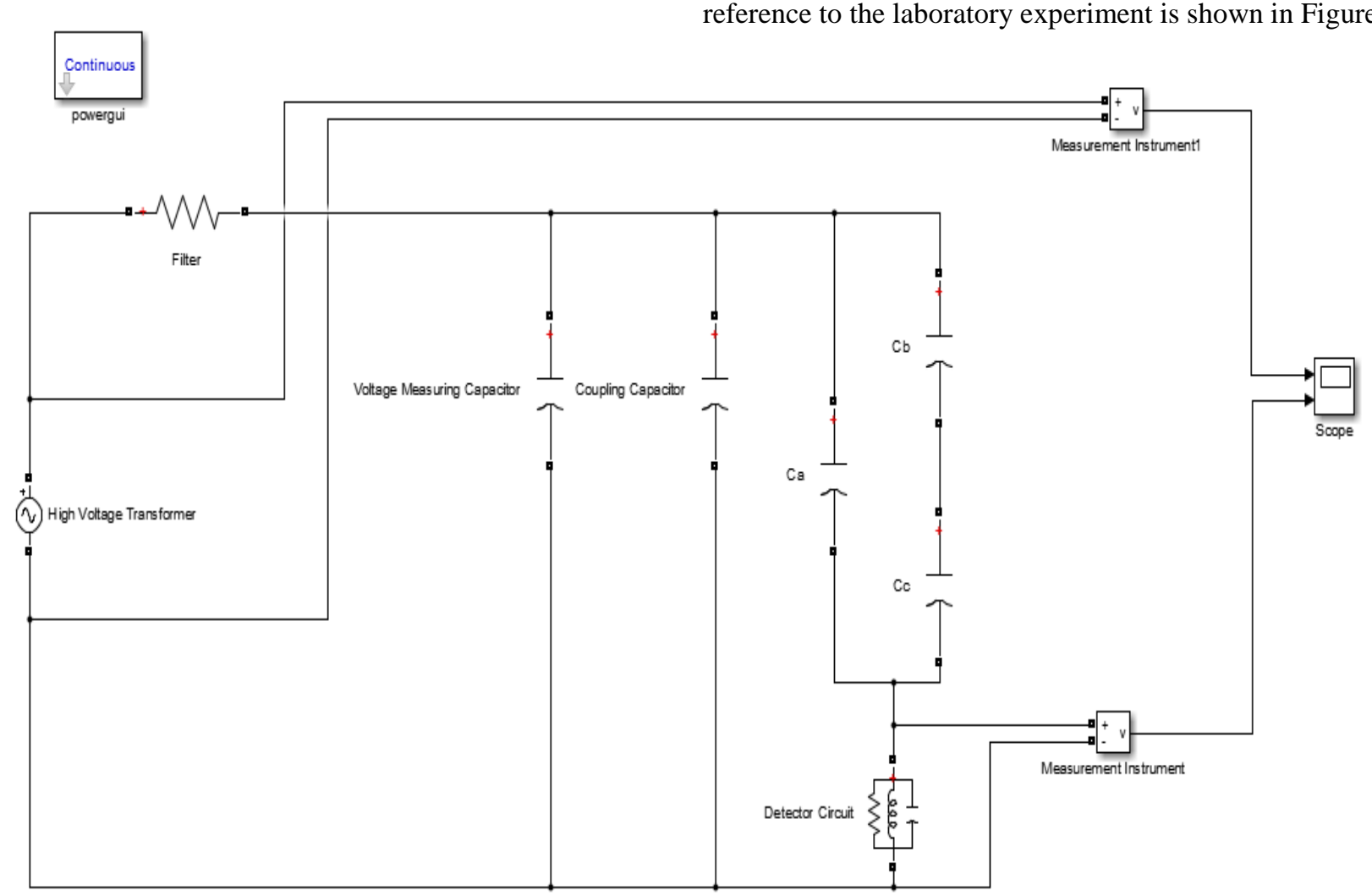

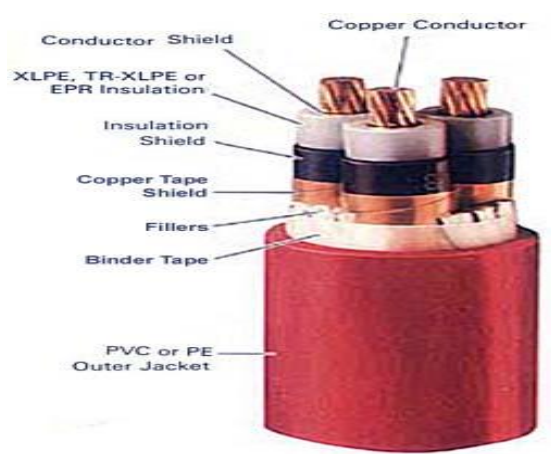

Figure 5 High Voltage Cable (Ametani, A et al., 2004)

Type tests are done on cable samples using both high voltages DC and impulse voltage. 1.8 times the rated DC rated in the DC test, the negative polarity voltage for 30 minutes, and the cable system is said to be fit, if it tolerates the test voltage.For impulse tests, impulse voltage of fixed magnitude is applied according to the specifications, and the cable has to face five applications without any loss. Generally, after impulse testing, power frequency dielectric power factor testing is done to ensure that there is no failure during impulse testing.

\section{EXPERIMENTAL RESULTS}

Electrical PD recognition and estimation strategy depends on the presence of PD voltage and current pulse in the proposed test object. So as to assess the major amounts of PD pulse, a simple capacitor circuit of cylindrical vacuum insulator is taken into consideration for this purpose. The simulink model for identification of PD in solid insulation in reference to the laboratory experiment is shown in Figure 6.

Figure 6 Simulink Setup for PD. 


\section{Partial Discharge Assessment of XLPE Cable}

The Figure 7 shows the Simulink result.

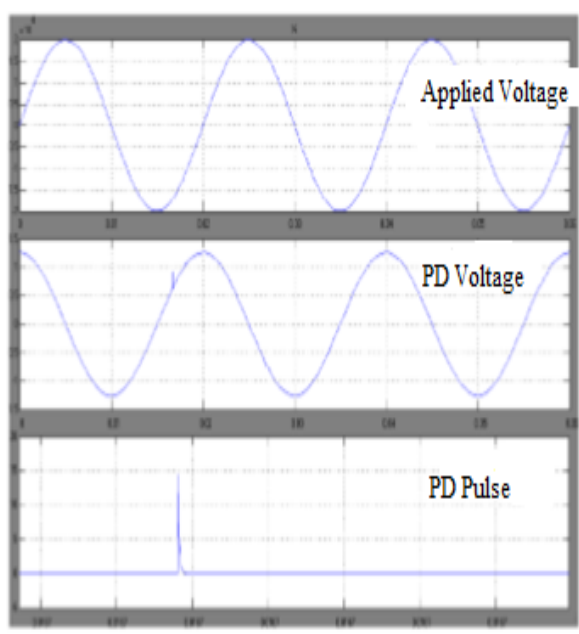

Figure 7 Simulink Result

\section{A. Results of Hardware Model}

The PD setup is shown in Figure 8 and Figure 9 in the high voltage lab of Thapar Institute of Engineering and Technology. The Figure8 shows the potential divider. The main part of the PD experiment is discharge capacitor and testing transformer as shown in Figure 9. The Table1 represents the Voltage $(\mathrm{kV})$ and discharge level of the XLPE cable.

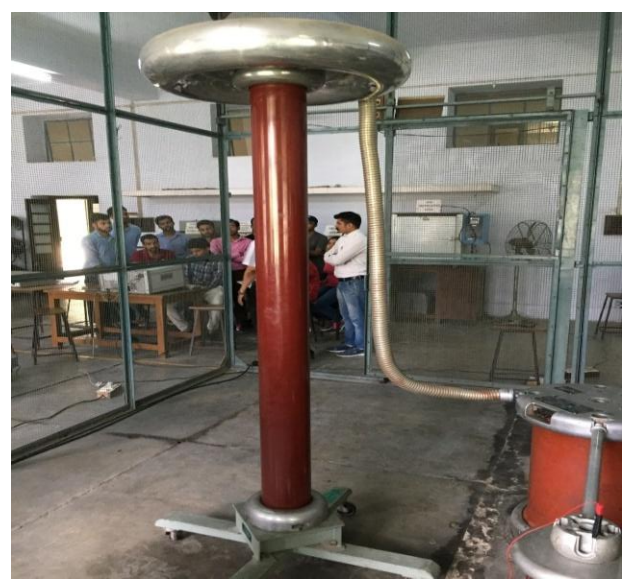

Figure 8 Potential Divider

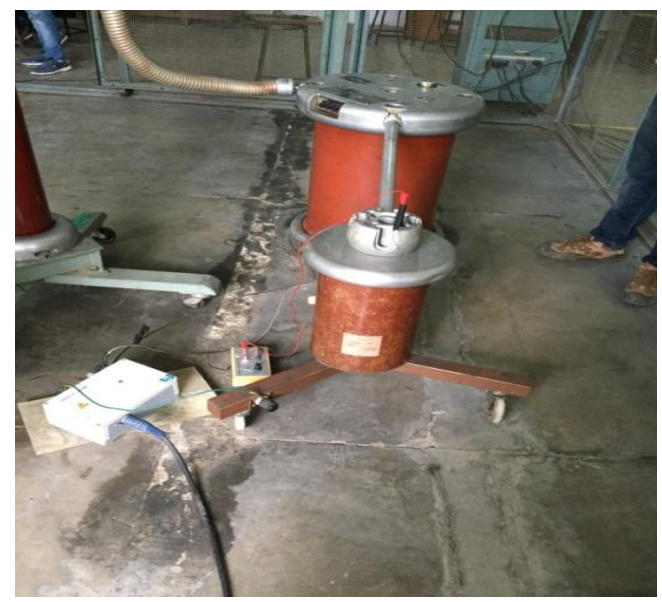

Figure9 Discharge Capacitor and Testing Transformer
Table 1 Break down voltage of cable and \%error

\begin{tabular}{cccccc}
\hline S.No. & $\begin{array}{c}\text { Voltage } \\
(\mathbf{k V})\end{array}$ & $\begin{array}{c}\text { Frequency } \\
\mathbf{( H z )}\end{array}$ & Discharge Level & $\begin{array}{c}\text { \% } \\
\text { Error }\end{array}$ \\
\hline & & & Experimental & Simulated & \\
$\mathbf{1}$ & 7.5 & 50 & $610 \mathrm{pC}$ & $609 \mathrm{pC}$ & 0.16 \\
$\mathbf{2}$ & 11.0 & 50 & $145 \mathrm{pC}$ & $147 \mathrm{pC}$ & -1.37 \\
$\mathbf{3}$ & 11.6 & 50 & $3.1 \mathrm{nC}$ & $2.9 \mathrm{nC}$ & 6.45 \\
$\mathbf{4}$ & 12.9 & 50 & $288 \mathrm{pC}$ & $289 \mathrm{pC}$ & -0.34 \\
$\mathbf{5}$ & 16.5 & 50 & $4.2 \mathrm{nC}$ & $4.1 \mathrm{nC}$ & 2.38 \\
$\mathbf{6}$ & 17.8 & 50 & $455 \mathrm{pC}$ & $457 \mathrm{pC}$ & -0.43 \\
\hline
\end{tabular}

${ }^{*} \mathbf{p C}=$ Pico coulomb, $*$ nC $=$ Nano coulomb

In the Table 1 the percentage error is calculated between the experimental and simulated values. The percentage error comes in between the -1.37 to 6.45 . The Table 2 and Table 3 represent the statistical parameters of the experimental and simulated values. In this, the standard deviation and mean is calculated. The Table 4 represents the instantaneous breakdown voltage of XLPE cable with different readings of the experimental values. This table helps in predicting the uncertainty of the experiment conducted on XLPE cable. The same is represented in graphical form in Figure 10. The uncertainty comes because of the variation in atmospheric temperature, pressure and dust. The average value is $610 \mathrm{PC}$ and all other value fall in a close range comes near this value.

Table 2.Statistical Parameters of Experimental Values Sample Standard Deviation, $\mathbf{s} \quad 1.73391 \mathrm{e}-9$

\begin{tabular}{cc}
\hline $\begin{array}{c}\text { Variance (Sample Standard), } \mathbf{s}^{2} \\
\text { Population Standard Deviation, } \boldsymbol{\sigma}\end{array}$ & $3.00645 \mathrm{e}-18$ \\
\hline $\begin{array}{c}\text { Variance (Population Standard), } \boldsymbol{\sigma}^{2} \\
\text { Total Number, } \mathbf{N}\end{array}$ & $6.50538 \mathrm{e}-9$ \\
Sum & $6.789 \mathrm{e}-9$ \\
Mean (Average) & $1.46633 \mathrm{e}-9$ \\
\hline Standard Error of the Mean & $7.07867 \mathrm{e}-10$ \\
\hline
\end{tabular}

Table 3.Statistical Parameters of Simulated Values

\begin{tabular}{cc}
\hline Sample Standard Deviation, $\mathbf{s}$ & $1.66478 \mathrm{e}-9$ \\
\hline Variance (Sample Standard), $\mathbf{s}^{2}$ & $2.77150 \mathrm{e}-18$ \\
Population Standard Deviation, $\boldsymbol{\sigma}$ & $1.51973 \mathrm{e}-9$ \\
Variance (Population Standard), $\boldsymbol{\sigma}^{2}$ & $2.30958 \mathrm{e}-18$ \\
Total Number, $\mathbf{N}$ & 6 \\
Sum & $8.502 \mathrm{e}-9$ \\
Mean (Average) & $1.417 \mathrm{e}-9$ \\
Standard Error of the Mean & $6.79645 \mathrm{e}-10$ \\
\hline
\end{tabular}

Published By:

Blue Eyes Intelligence Engineering DOI: 10.35940/ijeat.F8487.088619

Journal Website: www.ijeat.org

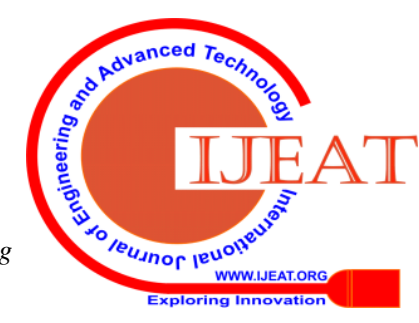


Table 4 Instantaneous Breakdown Voltage of XLPE cable

\begin{tabular}{ccccccc}
\hline Reading & $\mathbf{1}$ & $\mathbf{2}$ & $\mathbf{3}$ & $\mathbf{4}$ & $\mathbf{5}$ & $\mathbf{6}$ \\
\hline Breakdown & 610 & 609 & 608 & 610 & 610 & 609 \\
Voltage & $\mathrm{pC}$ & $\mathrm{pC}$ & $\mathrm{pC}$ & $\mathrm{pC}$ & $\mathrm{pC}$ & $\mathrm{pC}$ \\
\hline
\end{tabular}

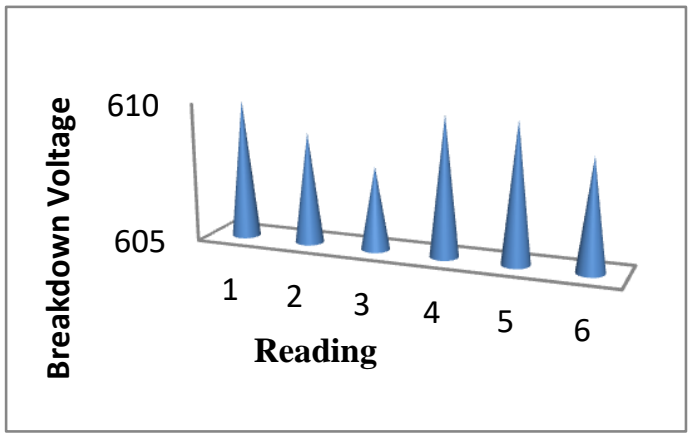

Figure 10 Uncertainty in Breakdown Voltage of XLPE
cable

\section{CONCLUSIONS}

To detect and measure the PD in solid insulation i.e. XLPE Cable the simulation is performed in this paper, and the results obtained have been compared with those obtained using the hardware experiment which is conducted at HAEFELY TRENCH in the High Voltage Laboratory of Thapar Institute of Engineering and Technology, Patiala (INDIA). The results of discharge levels for the test cable are taken at different voltage levels. Partial discharge equipment is used to measure the breakdown voltage of XLPE cable. From the obtained results, it is found that there is a small lapse of voltage waveform and PD pulse in the void of a solid insulation. The input voltage depends upon the discharge current. If the input voltage increases, then as a result, there is increment in the discharge current. The standard deviation and \%error are calculated. Hence, after the comparison of simulation and experimental results, it is safely concluded that the simulation model developed in the MATLAB is reasonably correct in simulating the real PD experimental setup. Also, it has been verified that PD increases with the increase in the voltage which is implicit and self-explanatory.

\section{ACKNOWLEDGEMENTS}

Thapar Institute of Engineering and Technology Patiala, India has well equipped laboratories for effective academic and research work. The authors are really grateful to the Thapar Institute of Engineering and Technology for providing the necessary support and facilities to carry out the work presented in this manuscript.

\section{REFERENCES}

1. Sharad, P. A., \& Kumar, K. S. (2017). "Application of Surface Modified XLPE Nanocomposites for Electrical Insulation of High Voltage Cables-Partial Discharge Study”. Energy Procedia, 117, 260267.

2. Singla, M. K., et.al. (2018).“Simulation and Experimental PD Study of Laboratory Test Setup”. Gucon, 395-399.

3. Sharad, P. A.,\& Kumar, K. S. (2016). "A review on nanocomposite based electrical insulations". Trans. Electr. Electron.Mater. (TEEM), 17(5), 239-251.

4. Naidu, M. S. (2013). “High voltage engineering”.Tata McGraw-Hill Education.
5. Weeks, W. L., \& Diao, Y. M. (1984)."Wave propagation characteristics in underground power cable". IEEE Transactions on Power apparatus and Systems, (10), 2816-2826.

6. Mugala, G., Eriksson, R., \&Pettersson, P. (2007). "Dependence of XLPE insulated power cable wave propagation characteristics on design parameters". IEEE transactions on dielectrics and electrical insulation, 14(2), 393-399.

7. De Mars, P. A., Kenrick, G. W., \& Pickard, G. W. (1930).“Lowfrequency radio transmission". Proceedings of the Institute of Radio Engineers, 18(9), 1488-1501.

8. Moore, P. J., Portugues, I. E., \& Glover, I. A. (2006). "Partial discharge investigation of a power transformer using wireless wideband radio-frequency measurements". IEEE Transactions on Power Delivery, 21(1), 528-530.

9. Patch, R., \& Hoof, M. (1998). "Physical Modeling of PD Patterns", IEEE International Conference on Conduction and Breakdown in Solid Dielectrics.

10. Kuffel, J., \& Kuffel, P. (2000). "High voltage engineering fundamentals".Elsevier.

11. Karmakar, S., \&Sabat, A. (2011)."International Journal on Electrical Engineering and Informatics". Simulation of Partial Discharge in High Voltage Power Equipment, 3(2).

12. Van Brunt, R. J. (1994). "Physics and chemistry of partial discharge and corona. Recent advances and future challenges". IEEE transactions on Dielectrics and Electrical insulation, 1(5), 761-784.

13. Bezborodko, P., Lesaint, O., \& Tobazeon, R. (1989)."On the mechanism of partial discharges in gaseous cavities in contact with solid or liquid insulators". In Proceedings of the 3rd International Conference on Conduction and Breakdown in Solid Dielectrics (pp. 392-396).IEEE.

14. Ametani, A., Miyamoto, Y., \& Nagaoka, N. (2004)."Semiconducting layer impedance and its effect on cable wave-propagation and transient characteristics". IEEE transactions on power delivery, 19(4), 1523-1531.

\section{AUTHORS PROFILE}

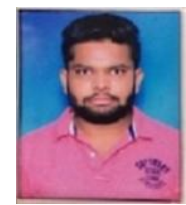

Manish Kumar Singla is PhD Scholar in the Electrical and Instrumentation Engineering Department at Thapar Institute of Engineering and Technology, India. He received his B.E. and M.E. degrees in Electrical Engineering from the Punjab Technical University and Thapar Institute of Engineering and Technology, in India, respectively. His current fields of interest include power systems, Artificial intelligence, High Voltage Engineering.

E-mail: msingla0509@gmail.com

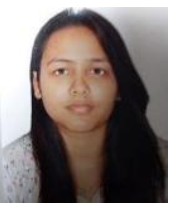

Jyoti Gupta is $\mathrm{PhD}$ Scholar in the Electrical and Instrumentation Engineering Department at Thapar Institute of Engineering and Technology, India. She received her B.E. and M.E. degrees in Electrical Engineering from the Punjab Technical University and Thapar Institute of Engineering and Technology, in India, respectively. Her current fields of interest include power systems, Artificial intelligence, Renewable Energy.

E-mail: jg118207@gmail.com

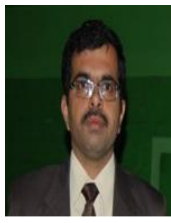

Dr. Parag Nijhawan is presently Associate Professor in the Electrical and Instrumentation Engineering Department at Thapar Institute of Engineering and Technology, India. He received his B.E. and M.E. degrees in Electrical Engineering from the Punjab Technical University and Punjab Engineering College in India, respectively. He did his PhD. in Electrical Engineering from National Institute of Technology, Kurukshetra. He has more than 18 years of work experience that includes teaching and research. His research focus includes renewable energy sources, power quality improvement, grounding and FACTS devices.

E-mail: parag.nijhawan@rediffmail.com

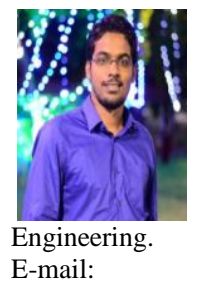

Dr. Ashish Paramane is presently doing his Post Doctoral at Zhejiang University, China. He did his PhD. from Vellore Institute of Technology, Chennai. He has more than 1 year of experience that includes teaching and research. His current fields of interest include power systems, High Voltage E-mail:

ashish.paramane@gmail.com 